\title{
HABILIDADES MATEMÁTICAS INICIAIS EM CRIANÇAS SURDAS E OUVINTES*
}

\author{
Heloiza H. Barbosa ${ }^{* *}$
}

RESUMO: O presente estudo tem como objetivo investigar o conhecimento de procedimentos e conceitos matemáticos em crianças surdas da educação infantil. Até o momento, existe uma grande escassez de estudos sobre o desenvolvimento de conceitos e procedimentos matemáticos em crianças surdas de idade pré-escolar. Os poucos trabalhos existentes sugerem que as crianças surdas têm dificuldades em aprender a sequência numérica. Contudo, não há qualquer evidência conclusiva a respeito das causas desta dificuldade. Os resultados deste estudo revelaram que as diferenças de desempenho entre crianças surdas e ouvintes estão relacionadas com a demanda linguística.

Palavras-chave: Matemática. Surdez. Crianças surdas. Educação infantil. Número.

\section{EARLY MATHEMATICAL ABILITIES IN HEARING AND DEAF CHILDREN}

ABSTRACT: This study investigated the understanding of mathematical procedures and concepts by deaf pre-school children. There are few studies centered on the development of Mathematical concepts and procedures by deaf pre-school children and these studies suggest that deaf children have difficulty learning number sequences. However, there is no conclusive evidence regarding the causes. The results

Esta pesquisa foi financiada pelo $\mathrm{CNPq}$ com bolsa de pós-doutoramento para a pesquisadora autora.

** Centro de Estudos Surdos, Universidade Federal de Santa Catarina (UFSC). Florianópolis (SC) - Brasil.

Contato com a autora: <heloiza@hbarbosa.org>

Cad. Cedes, Campinas, v. 33, n. 91, p. 333-347, set.-dez. 2013

Disponível em <http://www.cedes.unicamp.br> 
of this study show that differences in achievement between deaf and hearing children are related to linguistic demands. Therefore, deaf children have more difficulty in tasks with higher linguistic demand. Implications for the role of language in concept formation are discussed and supported by the data from this study.

Key words: Mathematical concepts. Deafness. Deaf children. Pre-school children. Number sequences.

\section{Problema de pesquisa}

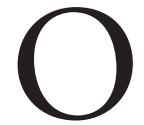

presente estudo tem como objetivo principal investigar o conhecimento de procedimentos e conceitos matemáticos em crianças surdas da educação infantil. Justifica-se pelos dados advindos de pesquisas acadêmicas que apontam para um fracasso escolar na área da matemática em crianças surdas. Vários estudos acadêmicos e levantamentos estatísticos (GREGORY, 1998; KLUWIN; MOORES, 1989; NOGUEIRA; ZANQUETTA, 2008; NUNES; MORENO, 1998; WOOD; WOOD; HOWART, 1983; TRAXLER, 2000) têm mostrado que crianças surdas apresentam um desempenho escolar inferior, ou abaixo da média, na área da matemática em comparação às crianças ouvintes, de mesma série e idade, que se desenvolvem tipicamente. Se este fracasso acontece em séries mais avançadas do ensino fundamental e em todas as séries do ensino médio, então é necessário investigar se o mesmo desnível de conhecimento matemático está presente no início da escolarização, ou seja, na educação infantil. Será que as crianças surdas chegam à educação infantil com o mesmo entendimento dos conceitos e procedimentos matemáticos (conhecimentos iniciais) que a criança não surda?

Em relação aos conhecimentos matemáticos iniciais, ou aqueles envolvidos na educação infantil, estudos feitos com crianças ouvintes desta faixa etária têm mostrado que antes do início da escolarização formal (ou seja, antes da primeira série), crianças constroem e adquirem uma vasta gama de conhecimentos, de base verbal e não verbal, sobre conceitos quantitativo-numéricos (GINSBURG; KLEIN; STARKEY, 1998). Assim, durante o período da educação infantil, crianças desenvolvendo-se tipicamente, aprendem nomes de números de um a dez, aproximadamente; aprendem os procedimentos da contagem, os objetivos da contagem, além de aprenderem sobre o conceito de equivalência - mais, menos e igual. 
Como pode ser visto, há uma vasta complexidade de conhecimentos matemáticos envolvidos no período da educação infantil. Portanto, é necessário investigar se a criança surda desta idade também tem acesso e constrói tais conhecimentos matemáticos iniciais.

Até o momento, existe uma grande escassez de estudos sobre o desenvolvimento de conceitos e procedimentos matemáticos feito com crianças surdas de idade pré-escolar. Os poucos trabalhos existentes sugerem que as crianças surdas têm dificuldades em aprender a sequência numérica (LEYBAERT; VAN CUTSEM, 2002; NUNES, 2004; ZARFATY; NUNES; BRYANT; 2004). Contudo, não há qualquer evidência conclusiva para dizer se esta dificuldade acontece devido a problemas de processamento cognitivo (HITCH; ARNOLD; PHILIPS, 1983), ou talvez seja devido ao pouco acesso a experiências envolvendo contagem em casa e na escola.

Muitas outras questôes relacionadas ao conhecimento quantitativonumérico das crianças surdas também precisam ser investigadas. Por exemplo, nós sabemos que é comum as crianças ouvintes cometerem alguns erros durante a aquisição do procedimento de contagem, mas não temos esta mesma informação em relação à criança surda. Portanto, precisamos saber que tipos de erros são comuns às crianças surdas. Nós precisamos saber, também, de que forma o conhecimento da sequência numérica influencia o desempenho da criança surda em testes numéricos, bem como precisamos ter mais informação sobre a relação entre língua de sinais e conhecimentos numéricos em crianças surdas.

Em relação a este ponto, pesquisas têm se ocupado em investigar como a língua produzida e compreendida na modalidade visuo-espacial, i.e., a língua de sinais, pode contribuir para o desenvolvimento cognitivo do indivíduo surdo, considerando os aspectos cognitivos que são mais ou menos dependentes do estimulo linguístico.

Em funçōes cognitivas menos dependentes do estímulo linguístico, crianças surdas e não surdas parecem ter um desenvolvimento similar. Esta hipótese tem sido reiterada por vários estudos na área que demonstraram que as crianças surdas apresentam um tempo e trajetória de desenvolvimento similar, ou até mesmo superior, ao das crianças ouvintes em: reconhecimento facial, construções com blocos lógicos, percepção de movimentos, memória espacial e localização espacial (BEVALIER et al., 2006; BLATTO-VALLEE et al., 2007; SATO et al., 2007). A superioridade no desenvolvimento destas funções cognitivas deve-se ao uso da língua de 
sinais que, por suas características visuo-espaciais, contribui positivamente para o desenvolvimento das habilidades de manipulação da informação visual e espacial (BULL et al., 2006; BLATTO-VALLEE et al., 2007). Crianças surdas que não são expostas a estímulos linguísticos e não recebem educação apropriada, em idade apropriada, não demonstram esta similaridade e superioridade no desenvolvimento destas funçóes cognitivas. Assim, ser exposta à língua de sinais desde pequena aumenta o desempenho da criança surda em funçôes cognitivas associadas com processamento visual. Isto, por conseguinte, pode refletir no desenvolvimento de conceitos matemáticos.

Foram essas questões que provocaram a realização desta pesquisa com crianças surdas e ouvintes da educação infantil. Esta investigação parece necessária se temos a intenção de promover bons níveis de rendimento escolar na área da matemática para todas as crianças e, assim, diminuir os desníveis de rendimento detectados entre crianças surdas e ouvintes.

\section{Metodologia}

\section{Localização e participantes}

O estudo foi conduzido como uma pesquisa de pós-doutoramento realizado na Universidade Federal de Santa Catarina (UFSC), pelo Núcleo de Investigação do Desenvolvimento Humano e Grupo de Estudos Surdos. A UFSC destaca-se como um centro de ensino e pesquisa de questóes relativas a esses estudos.

Quatro grupos de crianças surdas e não surdas participaram do estudo. Grupo 1: composto de 11 crianças surdas de idade média de 6 anos; Grupo 2: composto de 11 crianças ouvintes provenientes de centro público de educação infantil de idade média de 5 anos; Grupo 3: composto de dez crianças ouvintes provenientes de centro privado de educação infantil de idade média de 5 anos; Grupo 4: composto de 11 crianças ouvintes provenientes de centro público de educação infantil de idade média de 6 anos. A composição dos grupos de crianças ouvintes serviu de controle para as variáveis idade e tipo de escola. Parear crianças surdas com crianças ouvintes em estudos experimentais é sempre problemático devido à grande diversidade de perfil cognitivo entre as crianças surdas, principalmente. Por esta razão, o pareamento pela idade cronológica parece apropriado, 
apesar de também apresentar problemas. Para participar voluntariamente do referido estudo, os pais e/ou responsáveis pelas crianças assinaram um termo de consentimento.

\section{Procedimentos}

Cada criança participou, individualmente, de duas sessões de aproximadamente 60 minutos e cada sessão realizou-se com uma semana de intervalo. Uma estudante surda da pós-graduação, que usa a Língua Brasileira de Sinais (Libras) como sua língua nativa, foi treinada nas tarefas experimentais deste estudo e conduziu as sessōes com as crianças surdas. A principal investigadora deste estudo conduziu as sessões com as crianças ouvintes. Todas as sessôes foram filmadas para assegurar maior acuidade da coleta e análise dos dados.

Treze tarefas experimentais compuseram o estudo: 1) Pareamento quantitativo não verbal; 2) Reprodução de ordem sequencial visível; 3) Reprodução de ordem sequencial invisível; 4) Descrição de estímulo visual; 5) Recitação da sequência numérica até o maior número que souber; 6) Contar objetos soltos; 7) Contar conjuntos; 8) Contar ações; 9) Cardinalidade com objetos homogêneos e heterogêneos; 10) Equivalência da transformação numérica; 11) Adição; 12) Subtração e 13) Conhecimento da linha numérica. As tarefas de 1 a 5 constituíram a primeira parte do estudo, na qual o conhecimento quantitativo não simbólico e o conhecimento da sequência numérica foram investigados. As tarefas de 6 a 13 constituíram a segunda parte do estudo, que focou no conhecimento numérico per se dos participantes.

As crianças surdas também foram testadas em seu conhecimento de libras para assim correlacionar este conhecimento com o conhecimento matemático.

\section{Análise dos dados}

Análises qualitativas e quantitativas foram conduzidas. O desempenho das crianças nos testes foi computado em dois níveis: (1) pontos para acertos e (2) codificação das respostas para análise qualitativa. A pontuação quantitativa foi usada em análises comparativas de variáveis Anova (análise de variância) no modelo 4 (grupos) X 3 (variáveis dependentes). 


\section{Resultados}

Nas tarefas experimentais que focaram na representação quantitativa de base não linguística, não houve diferenças estatísticas entre os grupos de crianças surdas e não surdas em "Produção Não Verbal de Quantidades 3, 4, $6 \& 8$ ", $F(3,39)=1.81, p=.161$, "Reprodução de Ordem Seriada Visível - 3, 4, \& 6", $F(3,39)=.617, p=.608$ e "Reprodução de Ordem Seriada Invisível $-2,3, \& 4$ ", $F(3,39)=1.59, p=.205$. A Tabela 1 mostra as médias e desvios-padrão dos grupos. Isso significa que as crianças surdas e não surdas apresentam o mesmo nível de representação numérica quando o estimulo é de natureza não linguística.

Os resultados na Tabela 1 demonstraram, como esperado, que não há diferenças entre crianças surdas e ouvintes no que se refere às habilidades quantitativas não simbólicas. Isto significa que, durante a educação infantil, as crianças surdas e ouvintes demonstraram as mesmas capacidades quantitativas não simbólicas. Portanto, este resultado exclui a possibilidade de que a criança surda seja cognitivamente deficiente em seus conceitos quantitativos não simbólicos.

No entanto, quando o conhecimento quantitativo-numérico (simbólico) foi avaliado, houve uma significativa mudança. As crianças surdas tiveram um desempenho bem abaixo da média e estatisticamente diferente de alguns grupos de crianças ouvintes, mas não de todos. Por exemplo, as crianças ouvintes da escola pública de idade de 5 anos tiveram um desempenho nos testes numéricos tão baixo quanto o das crianças surdas.

Os dados das tarefas de contagem (contar objetos, figuras e ações) foram unificados para a criação da categoria Contagem, que aparece nos gráficos. $\mathrm{O}$ teste Anova revelou diferença entre os quatro grupos de participantes, $F(3,39)=12.05, p<.001$. O perfil das diferenças é o mesmo visto anteriormente, ou seja, as crianças surdas não diferem das crianças ouvintes de 5 anos da escola pública, pois ambos os grupos apresentam desempenho significativamente inferior aos demais grupos.

Todos os participantes tiverem mais dificuldades na contagem de figuras do que na contagem de objetos. Isto se deve a grande demanda na coordenação do "apontar" e "contar" quando se tem os conjuntos fixos em linha horizontal.

$\mathrm{Na}$ análise dos erros de contagem, foi possível perceber que a criança surda comete mais erros relacionados à sequência numérica. As crianças 
surdas, também, têm o seu limite de contagem mais claramente determinado; por exemplo, se a criança surda só sabe contar até dez e há um quadro de trinta figuras para ser contado, ao chegar no número dez as crianças param e dizem "acabou", ou recontam três vezes até dez sem juntar o resultado no final da contagem para informar a cardinalidade. As crianças ouvintes de 5 anos da escola pública foram as que cometeram erros em todas as modalidades de contagem e em todos os conjuntos. Contudo, seus erros estão mais relacionados à coordenação entre contar e apontar e, também, erros relacionados à cardinalidade. Era comum a criança ouvinte contar um conjunto e informar uma cardinalidade diferente da que foi verbalmente contada. Este tipo de erro de cardinalidade não foi cometido por nenhuma criança surda. Em geral, os resultados de contagem sugerem que tanto as crianças surdas, quanto as crianças ouvintes de 5 anos da escola pública parecem ter dificuldades em empregar o procedimento de contagem, e este fator pode ser um precursor de futuras dificuldades na aprendizagem da matemática.

O conhecimento de Libras influencia diretamente a habilidade de contagem. Como não há teste padronizado para Libras, um escore foi composto para este conhecimento que englobou: a) anos de conhecimento de Libras acessado pela família e b) uma classificação pelos professores do conhecimento de Libras de seus alunos surdos em três categorias: proficiente; em aquisição; não proficiente. Os testes estatísticos revelaram uma correlação positiva, na qual as crianças que têm mais conhecimento de Libras no grupo de crianças surdas são as que têm um melhor desempenho em contagem $F(1,9)=7.73, p=.021$, rs $(9)=.68, p=.021$. O coeficiente de correlação $r^{2}$ indica que o conhecimento de Libras explica $40 \%$ da variação dos escores de contagem.

$\mathrm{Na}$ tarefa da adição, houve diferença significativa entre os grupos, $F(3,39)=6.03, p=.002$. O teste post-hoc Tukey HSD detectou que as crianças surdas e as crianças ouvintes de 5 anos da escola pública tiveram um desempenho similar e mais baixo que as crianças dos demais grupos. As crianças surdas tiveram um desempenho inferior em relação às crianças ouvintes de 5 anos da escola privada $(p=.004, d=1.62)$ e às crianças mais velhas de 6 anos da escola pública $(p=.028, d=1.33)$. As crianças ouvintes de 5 anos da escola pública também tiveram um desempenho inferior em relação às crianças ouvintes de 5 anos da escola privada $(p=.029, d=.52)$.

$\mathrm{Na}$ tarefa de subtração, houve diferença significativa entre os grupos, $F(3,39)=3.41, p=.027$. No entanto, interessantemente, na subtração não 
houve diferença no desempenho das crianças surdas e os demais grupos. Em geral, as crianças surdas acharam mais fácil a subtração do que a adição. A diferença ficou entre as crianças ouvintes de 5 anos da escola pública e as crianças mais velhas da escola pública $(p=.036, d=1.36)$.

\section{Tabela 1}

Resultados da Anova

\begin{tabular}{|l|r|r|r|}
\hline \multicolumn{1}{|c|}{ Variáveis não línguísticas } & \multicolumn{1}{c|}{ Média } & \multicolumn{1}{c|}{ F } & \multicolumn{1}{c|}{ Sig. } \\
\hline Produção não verbal de quantidade total & 1.958 & 1.811 & .161 \\
Julgamento correto equivalência total & 2.190 & 1.556 & .215 \\
Vezes que empregou ação de consertar conjunto & .460 & 1.528 & .222 \\
Reprodução ordem seriada visível total & .432 & .617 & .608 \\
Tempo médio ordem seriada visível & 292.804 & 5.115 & .004 \\
Reprodução ordem seriada invisível total & 1.552 & 1.599 & .205 \\
Tempo médio ordem seriada invisível & 133.575 & 4.435 & .009 \\
\hline \multicolumn{1}{|c|}{ Variáveis línguísticas } & Media & $\mathrm{F}$ & \multicolumn{1}{|c|}{ Sig. } \\
\hline Vezes uso numeral em linguagem espontânea - org. padrão & 24.153 & 5.253 & .004 \\
Vezes uso numeral linguagem espontânea - org. aleatória & 283.987 & 10.044 & .000 \\
Total de contar objetos soltos & 10.762 & 9.832 & .000 \\
Total contar figuras & 12.714 & 10.231 & .000 \\
Total de ponto adição (máx. 4) & 7.211 & 6.029 & .002 \\
Total de pontos subtração (máx. 4) & 4.970 & 3.415 & .027 \\
\hline
\end{tabular}

A diferença de desempenho nos testes entre os dois grupos de crianças da escola pública e o grupo de crianças da escola privada é estatisticamente significativa. Estes resultados são visíveis nos gráficos que seguem.

As habilidades quantitativo-numéricas das crianças surdas apresentam-se em uma forte correlação com o conhecimento da criança sobre a Libras. Ou seja, as crianças que têm mais tempo de exposição a Libras e que têm elevado grau de fluência são aquelas que apresentam um desempenho mais elevado nos testes. Isto demonstra uma relação entre linguagem e formação de conceitos. Esta mesma correlação foi encontrada entre as 
crianças ouvintes. Por exemplo, as crianças com menor vocabulário foram as mais novas do centro de educação infantil público e estas foram as que tiveram mais baixo desempenho nos testes. As crianças mais novas do centro de educação infantil privado tiveram um desempenho bastante superior às crianças surdas, às crianças ouvintes de idade de 5 anos da escola pública e às crianças ouvintes de idade de 6 anos da escola publica em algumas tarefas, como o uso de vocabulário numérico, mas não em todas.

\section{Gráfico 1}

Média de contagem, aritmética e vocabulário para numerais entre os grupos

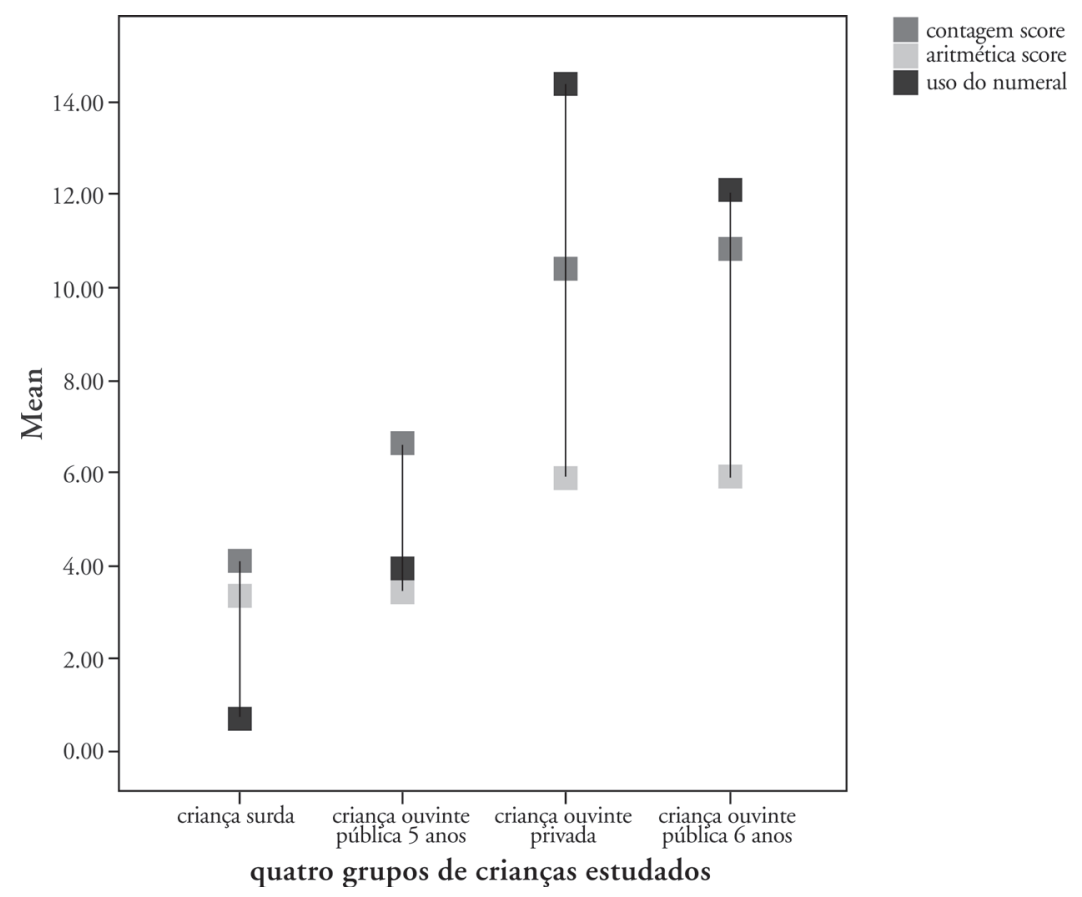

Em resumo, estes resultados sugerem que as crianças surdas se beneficiarão de um programa de ensino da matemática que faça uso de materiais concretos e visuais, os quais devem ser conectados e ancorados em suas fortes habilidades quantitativas não simbólicas. As crianças surdas 
também se beneficiariam de uma educação que fosse ministrada em sua língua nativa, a Libras, haja vista a forte correlação entre língua e formação de conceitos. Os resultados também sugerem que enormes esforços e investimentos precisam ser alocados para melhorar a educação matemática recebida por crianças surdas e ouvintes, oriundas de classes sociais menos favorecidas, que são atendidas nos centros públicos de educação infantil. $\mathrm{O}$ baixo desempenho destes dois grupos de crianças mostra a necessidade de uma intervenção imediata do governo para melhorar a aprendizagem e o desempenho destas crianças, surdas e ouvintes, que estão em grande risco de fracasso escolar.

\section{Gráfico 2}

Média de contagem entre os grupos

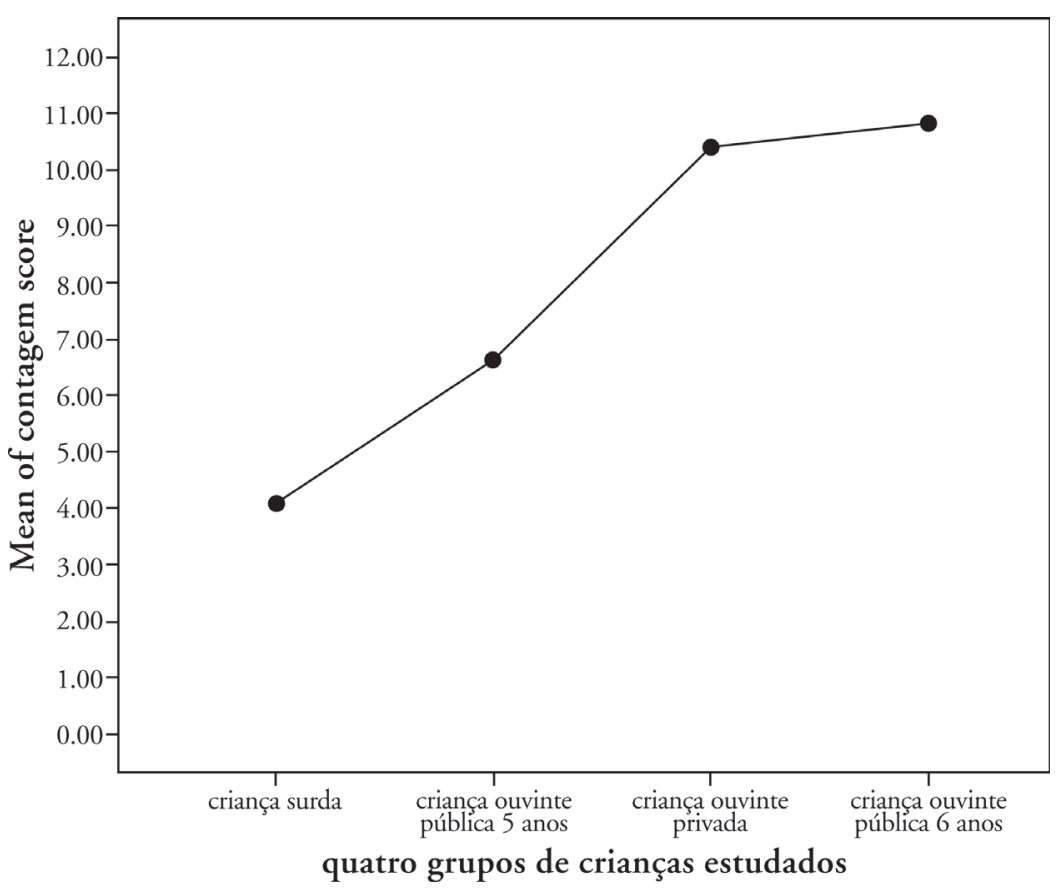




\section{Gráfico 3}

Média de contagem de figuras entre os grupos

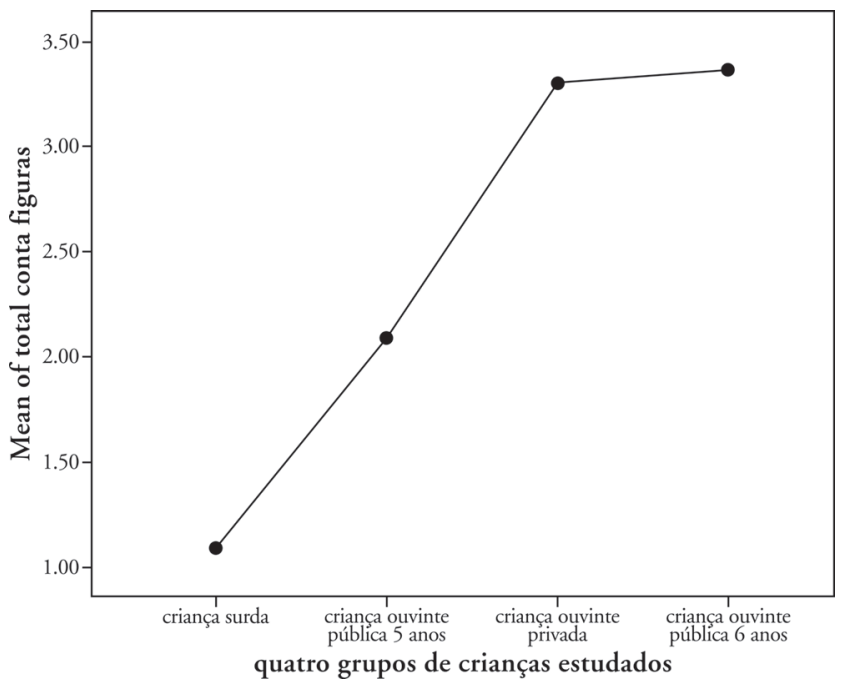

Gráfico 4

Média de contar objetos entre os grupos

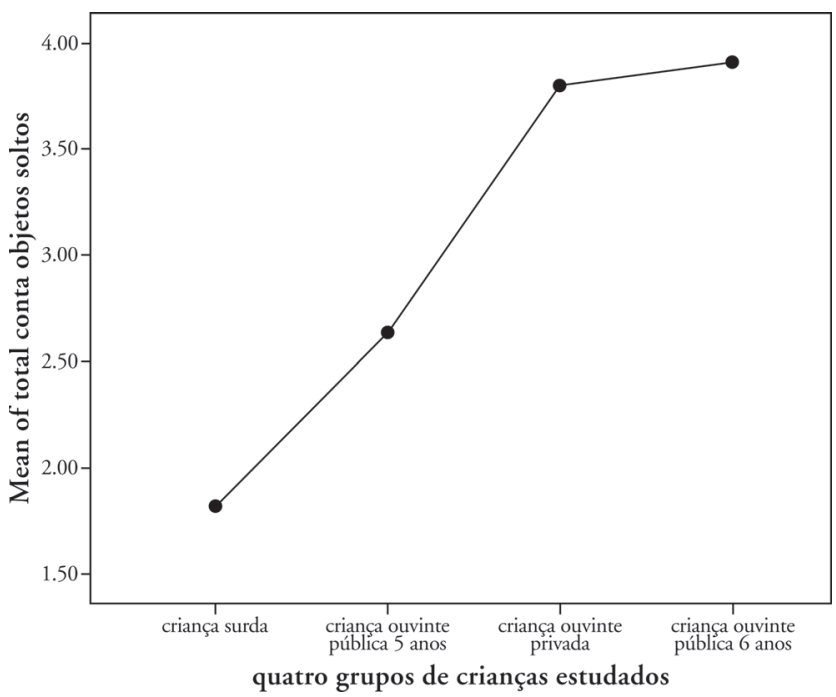

Cad. Cedes, Campinas, v. 33, n. 91, p. 333-347, set.-dez. 2013

Disponível em <http://www.cedes.unicamp.br> 
Habilidades matemáticas iniciais em crianças surdas e ouvintes

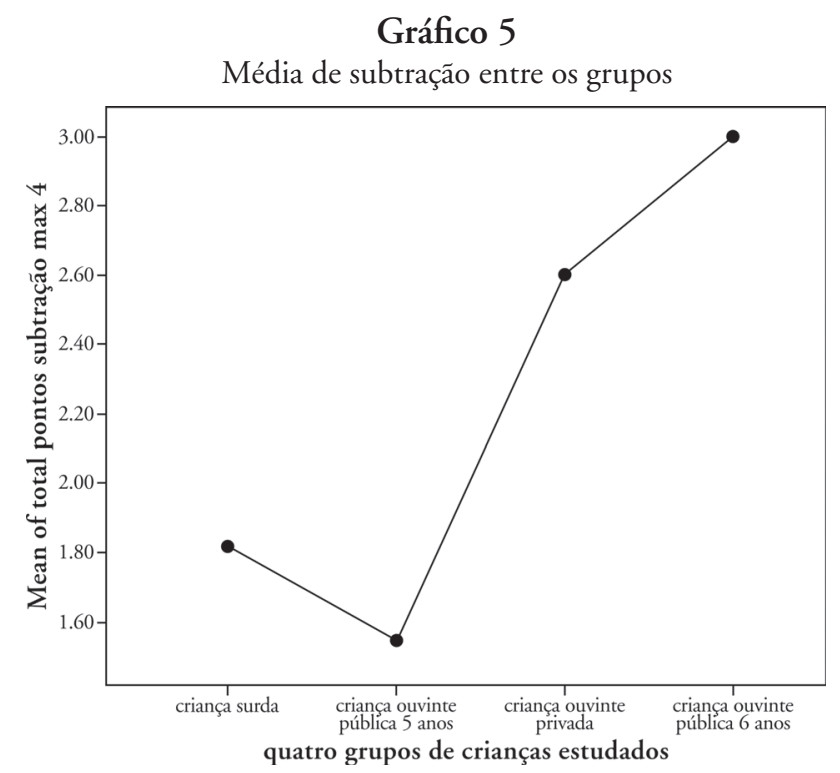

\section{Gráfico 6}

Correlação entre contagem e conhecimento de Libras

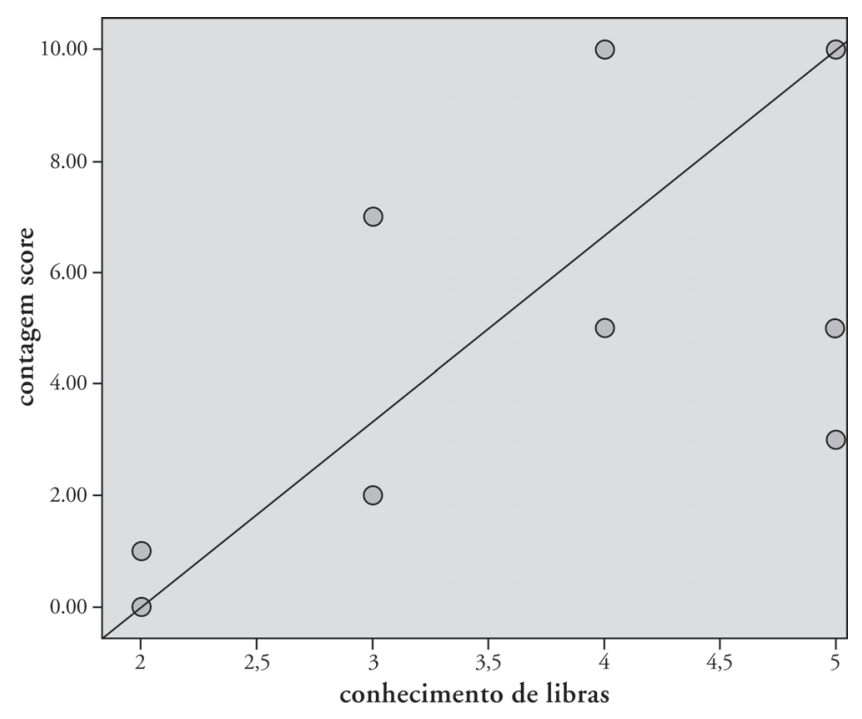




\section{Considerações finais}

O presente estudo revelou que não existem diferenças nas representações mentais quantitativas não simbólicas das crianças surdas e ouvintes. Quanto às habilidades quantitativas, o perfil se apresenta de forma mais complexa. As crianças surdas no geral tiveram um desempenho inferior em relação às crianças ouvintes mais velhas e às crianças ouvintes que frequentam a escola infantil privada. Mas não em relação às crianças mais novas da escola pública. Entretanto, os dados sugerem que mesmo que as crianças ouvintes da escola pública apresentem dificuldades em matemática, as mesmas parecem superar com mais tempo de escolarização, haja vista que as crianças mais velhas da escola pública apresentaram um bom desempenho. Todavia, mesmo o desempenho das crianças mais velhas da escola pública parece estar um ano abaixo do das crianças da escola privada (classe social mais privilegiada). Este quadro é extremamente preocupante, pois o problema não é de modalidade linguística ou processamento cognitivo, haja vista que tanto as crianças surdas quanto as ouvintes das classes sociais menos privilegiadas estão em risco de apresentarem dificuldades na aprendizagem da matemática. Os resultados sugerem que as dificuldades em matemática nos anos iniciais de aprendizagem das crianças surdas e das crianças ouvintes de classes populares são de natureza socioeconômicacultural e não cognitiva.

Às crianças surdas e às crianças da escola pública precisa ser ensinado vocabulário quantitativo-numérico. Esta prescrição deriva diretamente dos resultados deste estudo, pois, uma vez que essas crianças não têm o léxico para expressar ideias matemáticas, seu desenvolvimento nesta área pode ficar comprometido. Portanto, é essencial que as crianças sejam ensinadas, de forma significativa, sobre o vocabulário numérico-quantitativo-matemático e os conceitos que os mesmos expressam.

Assim, para diminuir o desnível de rendimento escolar na área de matemática entre crianças surdas e ouvintes das classes mais privilegiadas, é necessária a existência de programas educacionais na educação infantil que garantam condições de desenvolvimento para o conhecimento informal quantitativo numérico destas crianças. Para atender a tal necessidade, professores, especialistas e pesquisadores precisam de informaçóes sobre as dificuldades e facilidades que as crianças surdas têm ao aprenderem conceitos matemáticos. O presente estudo forneceu algumas destas informaçóes ao 
demonstrar que há necessidade de maior apoio em atividades que são mais dependentes do aspecto linguístico (vocabulário matemático). No entanto, mais pesquisas na área da cognição matemática em crianças surdas e ouvintes se fazem absolutamente necessárias para elucidação de áreas de maior risco de fracasso escolar. Faz-se necessário, também, em estudos futuros, criar metodologias e testes que controlem pela variação linguística, pois só assim podemos ter mais segurança nos resultados apresentados por estudos feitos com indivíduos surdos.

\section{Referências}

BEVALIER, D. et al. Persistent difference in short-term memory spam between sign and speech - implications for cross linguistic comparisons. Psychology Science, v. 17, n. 12, p. 1090-1092, 2006.

BLATTO-VALLEE, G. et al. Visual-spatial representation in mathematical problem solving by deaf and hearing students. Journal of Deaf Studies and Deaf Education, v. 12, n. 4, p. 432-448, 2007.

BULL, R.; BLATTO-VALLEE, G.; FABICH, M. Subitizing, magnitude representation and magnitude retrieval in deaf and hearing adults. Journal of Deaf Studies and Deaf Education, v. 11, n. 3, p. 289-302, 2006.

GINSBURG, H.P.; KLEIN, A.; STARKEY, P. The development of children's mathematical thinking: Connecting research with practice. In: DAMON, W.; SIEGEL, I.E.; RENNINGER, A.A. (Ed.). Handbook of Child Psychology. Child Psychology in Practice. New York: John Wiley, 1998. p. 401-76. v. 4.

GREGORY, S. Mathematics and deaf children. In: GREGORY, S. et al. (Ed.). Issues in deafeducation. London, UK: David Fulton, 1998. p 119-126.

HITCH, G.J.; ARNOLD, P.; PHILIPS, L.J. Cognitive processes in deaf children's arithmetic. British Journal of Psychology, n. 74, p. 429-37, 1983.

KLUWIN, T.N.; MOORES, D.F. Mathematics achievement of hearing impaired adolescents in different placements. Exceptional Children, n. 55, p. 327-35, 1989. 
LEYBAERT, J.; VAN CUTSEM, M.N. Counting in sign language. Journal of Experimental Child Psychology, n. 81, p. 482-501, 2002.

NOGUEIRA, M.C.I.; ZANQUETTA, M.E. Surdez, bilinguismo e o ensino tradicional de matemática: uma avaliação piagetiana. Zetetiké, Campinas, v. 16, n. 30, p. 219-237, jul./dez. 2008.

NUNES, T. Teaching mathematics to deaf children. London, UK: Whurr, 2004.

NUNES, T.; MORENO, C. Is hearing impairment a cause of difficulties in learning mathematics? In: DONLAN, C. (Ed.). The development of mathematical skills. Hove, UK: Psychology Press, 1998. p. 227-254.

SATO, M. et al. Numbers within our hands: modulation of corticospinal excitability of hand muscles during numerical judgment. Journal of Cognitive Neuroscience, v. 19, n. 4, p. 684-693, 2007.

TRAXLER, C.B. The Stanford Achievement Test. 9. ${ }^{\mathrm{h}}$ ed. National norming and performance standards for deaf and hear-of-hearing students. Journal of deaf Studies and Deaf Education, n. 5, p. 337-48, 2000.

WOOD, D.; WOOD, H.; HOWARTH, P. Mathematical abilities of deaf school leavers. British Journal of Developmental Psychology, n. 1, p. 67-73, 1983.

WOOD, H. et al. The mathematical achievement of deaf children from different educational environments. British Journal of Educational Psycho$\log y$, n. 54, p. 254-64, 1984.

ZARFATY, Y.; NUNES, T.; BRYANT, P. The performance of young deaf children in spatial and temporal number tasks. Journal of Deaf Studies and Deaf Education, 2004.

Recebido em 30 de maio de 2013.

Aprovado em 30 de setembro de 2013. 